IZA DP No. 1533

The Struggle over Migration Policy

Gil S. Epstein

Shmuel Nitzan

March 2005 


\title{
The Struggle over Migration Policy
}

\author{
Gil S. Epstein \\ Bar-llan University, CEPR \\ and IZA Bonn \\ Shmuel Nitzan \\ Bar-Ilan University

\section{Discussion Paper No. 1533 \\ March 2005}

\author{
IZA \\ P.O. Box 7240 \\ 53072 Bonn \\ Germany \\ Phone: +49-228-3894-0 \\ Fax: +49-228-3894-180 \\ Email: iza@iza.org
}

\begin{abstract}
Any opinions expressed here are those of the author(s) and not those of the institute. Research disseminated by IZA may include views on policy, but the institute itself takes no institutional policy positions.

The Institute for the Study of Labor (IZA) in Bonn is a local and virtual international research center and a place of communication between science, politics and business. IZA is an independent nonprofit company supported by Deutsche Post World Net. The center is associated with the University of Bonn and offers a stimulating research environment through its research networks, research support, and visitors and doctoral programs. IZA engages in (i) original and internationally competitive research in all fields of labor economics, (ii) development of policy concepts, and (iii) dissemination of research
\end{abstract} results and concepts to the interested public.

IZA Discussion Papers often represent preliminary work and are circulated to encourage discussion. Citation of such a paper should account for its provisional character. A revised version may be available directly from the author. 
IZA Discussion Paper No. 1533

March 2005

\section{ABSTRACT}

\section{The Struggle over Migration Policy*}

In this paper we analyze the endogenous determination of migration quota viewing it as an outcome of a two-stage political struggle between two interest groups: those in favor and those against the proposed migration quota. We first compare the proposed policies of the two interest groups under random behavior of the government, with and without lobbying. The paper proceeds with the examination of the effect of government intervention in the proposal of the quota on its nature, assuming that, with and without government intervention, the uncertain approval of the proposal is the outcome of a lobbying contest between the two interest groups. Finally, we examine the effect that the status-quo policy has on the proposed government's policy.

JEL Classification: J61, J81

Keywords: migration quota, interest groups, government intervention

Corresponding author:

Gil S. Epstein

Department of Economics

Bar-llan University

52900 Ramat-Gan

Israel

Email: epsteig@mail.biu.ac.il

*We are grateful to Ira Gang and to two anonymous referees for their constructive comments. 


\section{Introduction}

The effect of migration on the host countries is usually unclear. There exists a large literature on the effect migrants have on the local population, see for example, Benhabib (1996), Borjas (1994), (1995), Gang and Rivera-Batiz (1994), Schmidt, Stilz, and Zimmermann (1994), Zimmermann (1995) and more recently, Boeri, Hanson and McCormick (2002). One thing is apparent, except in unusual circumstances, Western countries tend to spend significant resources towards limiting the number and/or type of immigrants they allow into their countries. These limits are upheld via both border controls, through which undesired people are blocked from entering, and via internal enforcement, whereby undesired people are apprehended and expelled from the country (see, for example, Ethier (1986)).

Whatever way you look at it, whether migration has a positive, negative or no effect on the host country, the number of migrants in different western counties is very high. For example, in 1998 Denmark had 256,000 migrants that constituted 2.5\% of the population, Finland 552,000 (1.6\%), the UK 2,208,000 (3.8\%), Belgium 892,000 (8.7\%), France 3,231,000 (6.3\%), Switzerland 1,347,000 (19\%), Germany 7,319,000 (8.9\%) ${ }^{1}$ and over 11.7 million foreign-born workers in the US ${ }^{2}$. Moreover, there are many concentrations of migrants of the same origin in different host countries. For instance, there are concentrations of Turks in Germany, Tamils in Switzerland, Moroccans in the Netherlands and Belgium, Italians in Argentina, Greeks in Australia and Ukrainians in Canada. There are also more specific instances where emigrants from a certain town or region concentrate in the same foreign town or region. One of many such examples is the Macedonians from Skopje who have come to make up a sizable part of the population of Göteburg in Sweden. Such concentrations of migrants often cause xenophobia.

Empirical evidence from the EU countries shows that immigration had at most a very small impact on wages and employment opportunities of natives. Nevertheless, in the 1997 Eurobarometer survey, immigration turns out to be one of the three most significant political or social issues. It is not surprising therefore that with a large number of migrants, the high unemployment rate in some of the host countries, xenophobia, and the perceived effect the migrants have on the local population

\footnotetext{
${ }^{1}$ In the middle of this century Germany was in need of workers, and actively sought temporary workers especially from Turkey. Many of these "temporary" workers remained in the country after the expiry of their contract.

${ }^{2}$ Source: Boeri, Hanson and McCormick (2002).
} 
(workers and capital owners), migration policy is becoming an important issue in some of the developed countries and, in particular, it has become a central issue in the elections held in these countries. Most of the evidence on the effect of immigrants on wages (and employment) for the US is also ambiguous in the sense that some studies show small positive effect and others small negative effect. This is the overall effect. Clearly, there are income-distribution effects (see Gang and Rivera-Batiz, 1994). The evidence is ambiguous. A summary of all the evidence was put together by the National Academy of Science, in a study that benefited from the participation of leading scholars in a book edited by Smith and Edmonston (1997). It identifies the economic gains and losses from immigration--for the nation, states, and local areas-and provides a foundation for public discussion and policymaking. Borjas who was a member of the committee wrote a book in 1999 in which his interpretation of the data was, basically, that immigration of low-skilled workers into the US explains substantial share of the deteriorating labor market position of low-skilled workers.

In order to understand better the ambiguity of the results, Dustmann and Preston (2004) broaden the economic argument, by allowing for consideration not only of factors relating to labor-market competition, but also of factors relating to public burden and efficiency considerations (they draw data from the European Social Survey (ESS)). Their analysis yields a set of interesting results. Their model suggests that economic self interest points to an assessment of the benefits and costs from immigration that encompasses not only labor market competition, but also taxes and public burden, as well as general welfare effects determined by efficiency considerations. Interpretations that focus solely on the competition aspect seem therefore quite narrow. Their empirical analysis supports findings in much of the previous literature of a strong relationship between education and more positive attitudes towards various issues relating to migration. They also find that the particular questions that focus on very particular concerns are all strongly related to the overall assessment of migration.

Therefore wages may well not be the only concern of the local workers. The utility of the local population may also be negatively related to the number of migrants as a result of xenophobia, desire not to interact with different cultures, the effect of the finance of public goods as well as welfare and distributional effects that adversely affect the local population 
Migration policy involves a large range of issues such as legal and illegal migrants, temporary and permanent migration, high skilled and low skilled migration and asylum seekers and family unification. Many studies have been carried out regarding the optimal migration policy and the effects that different migration policies might have on the host country. Concern has been focused on whether to impose capital and skill requirements on the migrants, Benhabib (1996), on the alternative future policy options, given past experience, Zimmermann $(1995)^{3}$, on whether a reform of immigration policy can alone resolve the fiscal problems associated with the aging of the baby boom generation, Storesletten (2000), on the preferred policy regarding temporary and illegal migration, Epstein (2003), Epstein, Hillman and Weiss (1999) and Hillman and Weiss (1999) and on the migration policy implications of efficiency wage setting, Epstein and Hillman (2003). Other implications of migration policy are studied in Boeri, Hanson and McCormick (2002) and Bauer and Zimmermann (2002), see also references therein.

Even though there is a large literature concerned about migration policy, there is only one study on how in practice migration policy is determined ${ }^{4}$. Amegashie (2004) has recently studied a model in which the number of immigrants allowed into a country is the outcome of a costly political lobbying process between a firm and a union using the all-pay auction contest.

As in Amegashie (2004), and following Epstein and Nitzan (2004, 2003, $2002 a)^{5}$, we present a political framework where the approval of a migration policy hinges on the lobbying efforts of the groups competing for the approval and rejection of the proposed policy. In contrast to Amegashie (2004), we develop three alternative frameworks that allow a general contest success function which is positively affected by the different lobbying efforts of the contestants. It is assumed that there are two interest groups: one against the proposed quota and the other in favor of it. Those against the migrants include: workers that fear that they will be adversely affected by migration, anti-immigrant groups, immigrants of previous generations that prefer not

\footnotetext{
${ }^{3}$ Zimmermann (1995) shows that there has been a limited positive effect on the labor market and thus there are only few alternative policy options in the future,

${ }^{4}$ For different aspects of the political economy of migration see Sollner (1999), Buckley (1996) and Cukierman, Hercowitz and Pines (1993).

${ }^{5}$ Lobbying is an important part of the policy making process in representative democracies, Grossman and Helpman (2001), Persson and Tabellini (2000). Several studies have addressed the issue to what extent lobbying affects policy? Modelling lobbying as a "menu-auction", Grossman and Helpman (1996) study a Downsian model of electoral competition where candidates choose policies to maximize their probability of winning the elections.
} 
to be joined by other migrants to the host country, etc. To simplify the discussion, we assume that this group is represented by the workers' union. On the other side stand the capital owners that prefer a higher migration quota than the workers. An example that illustrates such a situation is the different votes taken in Switzerland on limiting the number of migrants. On the $24^{\text {th }}$ of Spetember 2000, for example, there was a national vote on an initiative proposed by the right-wing party SVP to include the following passage in the constitution: "The government has to make sure that the proportion of foreigners living in Switzerland does not exceed 18 percent”6 $36 \%$ voted in favor and $64 \%$ against the initiative (with a participation rate of $45 \%$ in the vote). ${ }^{7}$

The objective of our paper is to look at political-economy considerations that determine migration quota. We base our work on the framework developed by Epstein and Nitzan (2004, 2005). We begin our analysis by considering the optimal migration quotas of the workers' union and the capital owners, assuming that each group behaves non-strategically, sincerely revealing its preferred policy. The support of these first best policies is plausible, if each group believes that its preferred policy has no effect on the implemented policy. We then examine the preferred policy proposals when the interest groups recognize that the approval or rejection of their preferred policy depends on their lobbying efforts. The first objective of the paper is to examine the effect of lobbying on the migration quota when the government is not involved in the proposal of the migration policy. We then introduce into the model a third player, a politician/bureaucrat who seeks to maximize a composite utility function that depends on two components: the expected social welfare and the lobbying efforts of the contestants. Both the welfare component and the lobbying component have a positive effect on the bureaucrat's utility. Our second objective is to determine the optimal migration quota in this extended setting and to clarify how does government intervention in the proposal of the quota affect its nature and how does a change in the weight assigned by the government to the public well being affect the endogenous determination of the migration quota. The effect of the existing status-quo on the determination of the proposed policy of the government and on the

\footnotetext{
${ }^{6}$ See http://www.admin.ch/ch/e/pore/index3.html

${ }^{7}$ Note that in Switzerland initiatives can be proposed by anyone (but not the government). The requirement to have a vote on them is that the proposers need 100,000 signatures of voters in order to prove that there is enough interest in the issue.
} 
probability of its approval or rejection has been neglected in the political economy literature. Our analysis of this effect clarifies that the stats-quo has an important role in determining the bureaucrat's proposal and the likelihood of its approval.

\section{The Preferred Non-Strategic Migration Quotas}

Migration affects both workers' earnings and utility and the profits of capital owners. Let us describe how migration quotas affect the two groups within a simple economic environment. As the number of migrants entering the host country increases, the labor market conditions change. Foreign labor (migrants) can be either complementary inputs or substitute inputs to local labor. In the former case, an increase in the number of migrants increases the equilibrium wages of the local workers and thus their utility. That is, when foreign and local labor are complements, an increase in the migration quota increases the local workers' utility. ${ }^{8}$ On the other hand, if foreign and local labor are substitutes, an increase in the migration quota decreases wages and, in turn, the utility of the local workers. ${ }^{9}$ In such a case the utility of the local workers is inversely related to the migration quota. We assume that, in general, the two types of labor can be complements only under low migration levels. If this occurs, then at a sufficiently high migration level, local and foreign labor become substitutes. ${ }^{10} 11 \mathrm{We}$ wish to note that, in contrast to the local population, an increase in the population of the immigrants increases the migration network externalities and, in turn, the utility of the migrants in the host country and, at the same time, it decreases the cost for other migrants to join the previous migrants at the host country (see for example, Gottlieb 1987, Church and King 1993 Carrington, Detragiache, and Vishwanath, 1996 and Chiswick and Miller 1996).

Denote the migration quota by $Q$ and a representative worker's utility by $u_{w}$. The northwest quadrant (quadrant II) of Figure 1 presents the relationship between the migration quota and the utility of the local worker. For low migration quotas, there is

\footnotetext{
${ }^{8}$ In an efficiency model where the migrants are the unemployed, for certain levels of migration, an increase in the quota increases the utility of the local population, Epstein and Hillman (2003).

${ }^{9}$ This utility may not be the actual one, but the perceived utility - the utility the local population expect under a given migration quota.

${ }^{10}$ We will discuss later the case where the profits of the capital owners continue to increase as a result of an increase in the number of migrants.

${ }^{11}$ Even though we only discuss the direct labour market effect of migration, there may be other effects such as xenophobia, desire to refrain from interaction with different cultures, the effect of the finance of public goods as well as welfare and distributional effects that adversely affect the local population (for a more detailed analysis, see the Introduction).
} 
a positives relationship between the quota and the local worker' utility. However, beyond the quota $Q_{w}{ }^{*}$, an increase in the quota decreases the utility of the local worker, as the two types of labor become substitutes. Note that the utility of the local worker can be negative, although in the Figure it is assumed to be positive and that it may well be the case that the local and foreign labor are always substitutes, in which case the curve in the Figure is everywhere downward sloping.

Migration of foreign labor increases the capital owner's profits. When the two types of workers are substitutes, the increase in the labor supply decreases wages, and therefore production and the capital owners' profits are increased. It is assumed that even when the two types of workers are complements, allthough migration may increase wages, profits increase. Hence, capital owners always prefer an increase in the migration quota. Such an increase does not mean that the producers have to employ all the workers. It may well be that, due to the existence of government intervention, the marginal value of production is smaller than the cost of employing more workers. For example, in the case of minimum wage, the producer may only employ workers that contribute nonnegative marginal profit to the firm (the value of their marginal product exceeds the minimum wage). In such a situation an increase in the migration quota does not increase nor decrease the profits of the firm (we ignore the possibility that the burden of unemployed workers on the economy adversely affects the employers reducing their profits). Denoting by $u_{k}$ the utility of the capital owners, the southeast quadrant of Figure 1 presents the assumed positive relationship between the migration quota and the utility of the capital owners up to the quota $Q_{k}{ }^{*}$.

The northeast quadrant describes the relationship between the utility of the capital owner and the utility of the local workers. Both utilities increase with the migration quota in the interval $\left[0, Q_{w}{ }_{w}\right]$. Beyond $Q_{w}{ }^{*}$, but below $Q_{k}{ }^{*}$, an increase in the migration quota decreases the utility of the local workers while increasing the utility of the capital owners. Increasing the migration quota beyond $Q_{k}{ }^{*}$ continues to reduce the utility of the workers, however, such an increase has no effect on the utility of the capital owners. As already noted, the utility of the local workers can always decrease with the quota and the utility of the capital owner may always decrease with the quota. ${ }^{12}$

\footnotetext{
${ }^{12}$ These type of results can also be derived from a Heckscher-Ohlin international-trade model allowing iinternational factor mobility (see Mundell, 1957).
} 
In our models, competition between the two interest groups is over the migration quota. It is clear that both groups prefer the quota $Q_{w}{ }^{*}$ to any smaller quota. A conflict of interests only arises when the governemnt contemplates a migration quota that exceeds $Q_{w}{ }^{*}$. We therefore confine our analysis to the determination of migration quotas that are higher than $Q_{w}{ }^{*}$.

\subsection{The Rationale of Creating a Contest Between the Interest Groups.}

The government could decide to select the policy that results in the realization of the above migration quotas, i.e., to select the policy that generates the highest benefit to one of the interest groups: the stake $n_{H}$ for group $H$ ( $H$ for the group with the higher stake). The group with the lower stake is denoted group $L$. An alternative option for the government is to choose randomly between the two different policies that it faces. Even though the government chooses randomly, the interest groups may affect the choice probabilities. Clearly, if the utility the government derives from the selection of a policy is positively related to the aggregate net payoffs (stakes) of the interest groups, then it would never randomize, that is, it would select the policy that generates the higher stake. The probabilities of realization of the two policies in the complete-information public-policy contest are given by the contest success function (CSF). This function specifies the relationship between the interest groups' investment in the so called influence, lobbying or rent-seeking activities and the probability of realization of the two policies. The expected payoff of interest group $i$ is given by $E\left(u_{i}\right)$ and the effort invested by each interest group is denoted by $x_{i}$. (latter on in the paper we examine the relationship between the CSF, $E\left(u_{i}\right)$ and $\left.x_{i}\right)$.

As commonly assumed in the recent political economy literature, Grossman and Helpman (2001), Persson and Tabellini (2000), let the government's objective function be a weighted average of the expected social welfare and lobbying efforts:

$$
G(.)=\alpha\left(E\left(u_{L}\right)+E\left(u_{H}\right)\right)+(1-\alpha)\left(x_{L}+x_{H}\right)
$$

The parameters $\alpha$ and (1- $\alpha$ ) are the weights assigned to the expected social welfare and the contestants' lobbying outlays. If the government decides not to generate a contest and choose the policy that results in the higher stake $n_{H}$, then the value of the 
government's objective function is equal to $\alpha n_{H}$. It is therefore sensible for the government to create a contest if and only if the expected value of its objective function increases as a result of the existence of the contest. That is,

$$
\alpha\left(E\left(w_{L}\right)+E\left(w_{H}\right)\right)+(1-\alpha)\left(x_{L}+x_{H}\right)>\alpha n_{H}
$$

In Epstein and Nitzan (2002b) it is shown that, if the weight assigned to the lobbying outlays is greater than that assigned to the expected stakes, a contest based on a CFS such as the commonly assumed all-pay auction or Tullock's lottery logit functions can be preferable to no contest that is, random government behavior is therefore rational

\section{The Effect of Lobbying: No Government Intervention in the Proposal Process}

Suppose that a status-quo policy regarding the migration quota is challenged by the capital owners and defended by the worker's union. The workers' union, the defender of the status-quo policy, (henceforth interest group $w$ or, simply, the workers) prefers the status-quo policy $Q_{w}{ }^{*}$ to any alternative policy. The capital owners, (interest group $k$ ) prefers the alternative policy $Q_{k}{ }^{*}$. As argued above, $0<Q_{w}{ }^{*}<Q_{k}{ }^{*}$. It is assumed that the policy $Q_{w}{ }^{*}\left(Q_{k}{ }^{*}\right)$ is the optimal policy proposal of the workers (the capital owners), provided that their supported policy gains certain approval. That is, each interest group disregards the possibility that its preferred policy can be rejected, in which case the policy supported by the rival interest group is assumed to be approved. More generally, these quotas are preferred by the interest groups whenever they believe that the approved and implemented policy is independent of their behavior and, in particular, of their revealed preferred policies and the influence activities that are intended to promote the implementation of these preferred policies. In Figure 1 these most preferred policies and the corresponding utilities are represented, respectively, by point $\mathrm{A}$, for the workers' union and point $\mathrm{B}$, for the capital owners. ${ }^{13}$

Under effective lobbying, the actual implemented policy depends on the contest between the workers' union and the capital owners and on the approval of their proposed policies. The equilibrium proposed policies, that are endogenously

\footnotetext{
${ }^{13}$ In a similar way, in the contest over monopoly regulation studied in Baik (1999), Ellingsen (1991) and Schmidt (1992), the monopoly firm is assumed to defend the status-quo, its profit- maximizing price (against any price regulation), while the consumers challenge the status-quo lobbying for the competitive price (a tight price cap).
} 
determined in our first alternative strategic settings, are denoted $Q_{k}{ }^{* *}$ and $Q_{w}{ }^{* *}$. The outcome of the political contest is given in terms of the probabilities $P r_{k}$ and $P r_{w}$ that the workers and the capital owners win the contest. The outcome of the contest depends on the stakes of the contestants and, in turn, on their proposed policies and on their exerted lobbying or rent-seeking efforts. The important role of the political environment (the form of the government, its motivation and the decision rule it applies) is represented by the commonly used contest success function that specifies the relationship between the outcome of the contest and the proposed policies or the efforts of the interest groups.

As in Epstein and Nitzan (2004), the workers and capital owners make two types of decisions. In the first stage of the game, the interest groups non-cooperatively select their proposed policies, the lobbying targets, $Q_{k}$ and $Q_{w}$. In the second stage they engage in a contest over the approval of the proposed policies. The interest groups are assumed to pre-commit to their proposed policies and the commitments are feasible and are fully implemented after the contest. ${ }^{14}$ The means of the workers and capital owners to affect the outcome of the contest, viz. their winning probabilities, in the second stage of the game is their lobbying or rent-seeking efforts $x_{k}$ and $x_{w} \cdot{ }^{15}$ The approval of the policy proposals $Q_{k}$ and $Q_{w}$ imply different utilities for the two interest groups. The benefit of the capital owners is $v_{k}\left(Q_{k}\right)$, if its proposal is approved and $v_{k}\left(Q_{w}\right)$, if the workers' union proposal is approved. In a similar way, the benefit of the workers' union is $v_{w}\left(Q_{w}\right)$, if its proposal is approved and $v_{w}\left(Q_{k}\right)$, if the capital owners' proposal is approved. The workers' union's and the capital owner's expected payoffs are given by:

$$
E\left(u_{j}\right)=\operatorname{Pr}_{i} v_{j}\left(Q_{i}\right)+\operatorname{Pr}_{j} v_{j}\left(Q_{j}\right)-x_{j} \quad \forall i \neq j, i, j=w, k
$$

or,

$$
E\left(u_{j}\right)=v_{j}\left(Q_{i}\right)+\operatorname{Pr}_{j} n_{j}\left(Q_{j}, Q_{i}\right)-x_{j} \quad \forall i \neq j, \quad i, j=w, k
$$

\footnotetext{
${ }^{14}$ For different rent-seeking games with an explicit time structure that allow for such commitment, see Baik and Kim (1997), Baye and Shin (1999) and Dixit (1987).

${ }^{15} X_{w}$ and $x_{k}$ are total lobbying efforts. An implicit assumption is thus made that the interest groups are able to fully overcome the free riding effects.
} 
where $n_{j}\left(Q_{j}, Q_{i}\right)$ is the stake of interest group $j$, that is, $n_{k}\left(Q_{k}, Q_{w}\right)=v_{k}\left(Q_{k}\right)-v_{k}\left(Q_{w}\right)$ and $n_{w}\left(Q_{k}, Q_{w}\right)=v_{w}\left(Q_{w}\right)-v_{w}\left(Q_{k}\right)$.

The utility functions $v_{k}$ and $v_{w}$ are assumed to be monotonic, continuous and twice differentiable on the interval $\left[Q_{w}{ }^{*}, Q_{k}{ }^{*}\right]$. Notice that when $Q_{w}=Q_{k}$ both stakes are equal to zero and that $\partial n_{k} / \partial Q_{w}<0$ and $\partial n_{w} / \partial Q_{k}>0$ on the interval $\left[Q_{w}{ }^{*}, Q_{k}{ }^{*}\right]$.

The function that specifies i's probability of winning the contest, $\operatorname{Pr}_{\mathrm{i}}\left(x_{i}, x_{j}\right)$, is usually referred to as a contest success function (CSF). This function is usually assumed to satisfy the following requirements, see Nitzan (1994): $\operatorname{Pr}_{k}+\operatorname{Pr}_{w}=1$ such that $\operatorname{Pr}_{i}\left(x_{i}, 0\right)=1 \quad \forall x_{i}>0, \quad 0<\operatorname{Pr}_{i}\left(x_{i}, x_{j}\right)<1 \quad \forall x_{i}, x_{j}>0, \quad \operatorname{Pr}_{i}(0,0)=0.5$, $\frac{\partial \operatorname{Pr}_{i}\left(x_{i}, x_{j}\right)}{\partial x_{i}}>0, \quad \frac{\partial \operatorname{Pr}_{i}\left(x_{i}, x_{j}\right)}{\partial x_{j}}<0$ and $\frac{\partial^{2} \operatorname{Pr}_{i}\left(x_{i}, x_{j}\right)}{\partial x_{i}{ }^{2}}<0$ (the latter inequality ensures that the second order conditions are satisfied). Since $\operatorname{Pr}_{i}\left(x_{i}, x_{j}\right)+\operatorname{Pr}_{j}\left(x_{j}, x_{i}\right)=1, \frac{\partial^{2} \operatorname{Pr}_{i}\left(x_{i}, x_{j}\right)}{\partial x_{i} \partial x_{j}}=-\frac{\partial^{2} \operatorname{Pr}_{j}\left(x_{j}, x_{i}\right)}{\partial x_{i} \partial x_{j}}$.

In our first two-stage game with complete information, a sub-game perfect equilibrium can be calculated by using a standard backward induction procedure. The equilibrium effort levels $x_{k}{ }^{* *}$ and $x_{w}{ }^{* *}$ are determined in the second stage. These equilibrium lobbying efforts, which are assumed to be interior and unique, satisfy the conditions: $\frac{\partial E\left(u_{i}\right)}{\partial x_{i}}=0 \quad, i=w, k$, that is,

$$
\Delta_{i}=\frac{\partial \operatorname{Pr}_{i}}{\partial x_{i}} n_{i}-1=0 \quad, i=w, k
$$

The interior equilibrium policy proposal $Q^{* *}$ and $Q^{* *}{ }_{w}$, which are determined in the first stage of the game, satisfy the conditions: $\frac{\partial E\left(u_{i}\right)}{\partial Q_{i}}=0, i=w, k$. Given (5), these conditions can be written as follows:

$$
\frac{\partial E\left(u_{i}\right)}{\partial Q_{i}}=\frac{\partial \operatorname{Pr}_{i}}{\partial x_{j}} \frac{\partial x_{j}}{\partial Q_{i}} n_{i}+\operatorname{Pr}_{i} \frac{\partial n_{i}}{\partial Q_{i}}=0
$$


It can be verified that the condition needed for applying the results in Epstein and Nitzan (2004) hold, thus by the two main results in Epstein and Nitzan (2004), as long as the two interest groups engage in a viable contest in the second stage of the game, in equilibrium they are induced to voluntarily moderate their proposals relative to their best policies when there is no opposition. Specifically, the equilibrium policies $Q^{* *}{ }_{k}$ and $Q^{* *}{ }_{w}$ satisfy: $Q^{* *}{ }_{k}<Q^{*}{ }_{k}$ and $Q^{* *}{ }_{w}>Q^{*}{ }_{w}$. Although polarization is reduced, it is not eliminated. That is, an equilibrium with completely converging proposed policies is impossible. To sum up,

Under uncertain effective lobbying with no government intervention in the proposal of the migration quota, the workers' union and the capital owners moderate their proposals. However, the equilibrium policy proposals do not coincide

This result, as mentioned above, is a specific case of the more general model presented in Epstein and Nitzan (2004). The intuition for this result is as follows: If there is no opposition the capital owners choose the policy $Q_{k}{ }^{*}$. In the presence of an opposition, the capital owners realize that lowering their proposal for migration quota below $Q_{k}{ }^{*}$ leads to a decrease in their payoff from winning the contest. But the more restrained proposal yields an increase in the payoff of the opponent and, in turn, a reduction in his stake that induces him to become less aggressive. The resulting decline in the workers' union's probability of winning the contest clearly benefits the capital owners. Since the latter favorable effect dominates the former unfavorable effect, the capital owners prefer to restrain their lobbying target, i.e., propose a policy below the migration quota of $Q_{k}{ }^{*}$. A similar intuition explains the readiness of the workers' union, the defender of the status-quo, to moderate its position by proposing a policy that exceeds $Q_{w}$. For both the workers and the capital owners, a deviation from any agreed upon compromise results in a first order increase in the expected payoff, $\operatorname{Pr}_{i}\left(Q_{i}, Q^{*}\right) n_{i}\left(Q_{i}, Q_{j}\right)$, and a second order reduction in the expected payoff, $-x_{i}$. Consequently, both interest groups are induced to deviate from any agreed upon proposal and conflict is a necessary outcome of the interaction in our game. Since there always remain effective incentives for the interest groups to engage in a viable contest, wasteful resources are expended in the second stage of the game. Note that 
the interest groups could, of course, increase their expected payoffs by agreeing to cut down their lobbying efforts by the same proportion. This implies that the equilibrium of the quota - determination game is inefficient.

\section{Government Intervention in Determining the Proposed Quota}

\subsection{Assuming a given status quo-policy}

Suppose now that the proposed migration quota is determined by the government (a bureaucrat) and not by the interest groups (see Epstein and Nitzan, 2005). In this alternative setting, the stakes of the two groups are equal to the utility differences of the interest groups corresponding to the status-quo and the proposed migration quotas. The stakes do not only depend on the proposed policy by the government, $Q^{+}$, but also on the status-quo policy: the stakes are defined as $n_{k}\left(Q_{k}, Q_{s}\right)=\left|v_{k}\left(Q^{+}\right)-v_{k}\left(Q_{s}\right)\right|$ and $n_{w}\left(Q^{+}, Q_{s}\right)=\left|v_{w}\left(Q^{+}\right)-v_{w}\left(Q_{s}\right)\right|$ where $Q_{s}$ is the status-quo policy. The status-quo, of course, affects both the stakes and the expected payoffs of the interest groups. In this sub-section we concentrate on the choice of the migration quota given a status-quo policy. In the next sub-section we will consider the effect of a change in the statusquo on the proposed policy. Clearly, a viable contest exists, if and only if the proposed policy differs from the status-quo

In general, the stakes of the contestants are different, that is, one of them has an advantage over the other in terms of his benefit from winning the contest. It is not clear which of the groups has a larger stake. The ratio $n_{w} / n_{k}$ is a measure of the asymmetry between the stakes of the contestants. By the expressions in (5) that determines the equilibrium efforts of the players and, in turn, their probabilities of winning the contest and by the assumed properties of the CSF, it is clear that under a symmetric contest success function ${ }^{16}\left(\forall x_{i}, x_{j}, \operatorname{Pr}_{i}\left(x_{i}, x_{j}\right)=\operatorname{Pr}_{j}\left(x_{j}, x_{i}\right)\right)$, the player with the higher stake makes a larger effort and has a higher probability of winning the contest.

By definition of the stakes (see eq. (3) and (4)) a change in the proposed migration quota affects the stakes of the players and, therefore, their efforts and

\footnotetext{
${ }^{16}$ Such symmetry implies that the two players share an equal ability to convert effort into probability of winning the contest.
} 
probability of winning the contest. Assuming that the stake functions $n_{i}(Q)(i=w, k)$ are continuous and twice differentiable in the quota $Q$, let $n_{i}^{\prime}=\frac{\partial n_{i}}{\partial Q}$. By assumption,

$$
\frac{\partial n_{w}}{\partial Q}>0 \text { and } \frac{\partial n_{k}}{\partial Q}>0 \text {, if } Q_{w}^{*} \leq Q \leq Q_{k}^{*}
$$

and

$$
\frac{\partial n_{w}}{\partial Q}>0 \text { and } \frac{\partial n_{k}}{\partial Q}=0, \text { if } Q_{k}^{*}<Q
$$

That is, an increase in the migration quota increases the utility of the capital owners and, in turn, their stake. Such an increase also increases the local workers' stake because an increase in quota decreases the utility of the workers so they have more to lose if the proposal is approved. Usually, a certain number of migrants is beneficial to the workers, see, for example, Epstein and Hillman (2002) and Epstein (2003). To simplify the analysis, we confine our attention to quota proposals beyond the quantity that improves the local workers' utility. By (8), an increase in the number of migrants beyond $Q_{k}^{*}$ is not beneficial to the capital owners, that is, an increase of the quota beyond $Q_{k}^{*}$ has no effect on the capital owners' utility. Consequently, the producers would not employ more than $Q_{k}^{*}$ foreign workers. We could envisage a situation where an increase in the number of migrants imposes a cost on the economy and, in particular, on the employers. This possibility, however, is also disregarded.

As in Epstein and Nitzan (2002a), anticipating the behavior of the interest groups in the second stage of the game, where the lobbying outlays are determined, the bureaucrat selects his strategy, that is, the proposed migration quota in the first stage of the game. In other words, he selects a policy proposal subject to the political constraint imposed by the bureaucrat, namely, subject to the contest on the approval of his proposal. In general, the bureaucrat's objective function reflects mixed commitments to the enhancement of the public well being and to his own self interest, which is represented herein by the contestants' lobbying outlays. As assumed in (1) the objective function $G($.$) is of the form$

$$
G(.)=\alpha\left(E\left(u_{w}\right)+E\left(u_{k}\right)\right)+(1-\alpha) X
$$


where $E\left(u_{w}\right)$ and $E\left(u_{k}\right)$ are the expected net payoffs of the workers and the capital owners. The contestants' total lobbying outlays, $X=x_{w}+x_{k}$, represent either transfers to the government (the bureaucrat and/or the regulator) or resources wasted in the contest. Note that taking into account the public interest is consistent with thebureaucrat being either benevolent or realistic (wishing to be re-elected). ${ }^{17}$ The utility of the bureaucrat is thus a weighted average of both welfare, $E\left(u_{w}\right)+E\left(u_{k}\right)$, and the total amount of the lobbying outlays, $X$. The parameters $\alpha$ and (1- $\alpha)$ are the weights assigned to the components corresponding to the expected social welfare and the contestants' lobbying outlays. The optimal migration quotas in the non-strategic setting of section 2 are represented by points A and B in Figure 2. The equilibrium quotas for the workers and the capital owners in the strategic game analyzed in the section 3 are represented, respectively, by points $A^{\prime}$ and B'. The equilibrium migration quota in the current game can be represented by a point like $\mathrm{C}$, a point like D or by any other point on the utility possibility frontier of Figure 2. A point like C implies that the intervention of the government in the proposal of the quota is compromise enhancing, both relative to the first non-strategic situation and relative to the strategic situation of the preceding section. A point like D implies that quota determination by the government may result in the approval of a quota that is more extreme both relative to $Q_{k}{ }^{*}$ and $Q_{k}{ }^{* *}$. The main concern of the analysis below is the question how does government intervention in the quota proposal affect the proposed quota.

The anticipated equilibrium lobbying efforts $x_{k}{ }^{+}$and ${x_{w}}^{+}$that are determined in the second stage of the game are characterized by conditions (5). The condition characterizing the sub-game perfect equilibrium migration quota $Q^{+}$(the quota that maximizes $G\left(\right.$.), given the anticipated lobbying outlays) is ${ }^{18}$ :

$$
\frac{\partial G(.)}{\partial Q}=\alpha \frac{\partial\left(E\left(u_{k}^{+}\right)+E\left(u_{w}^{+}\right)\right)}{\partial Q}+(1-\alpha) \frac{\partial X^{+}}{\partial Q}=0
$$

\footnotetext{
${ }^{17}$ In contrast to the recent literature on public policy determination in representative democracies, Grossman and Helpman (2001), Persson and Tabellini (200o), in our two-stage reduced-form public policy contest, the effect of the often elaborate relationship between the public well being and the probability of re-election on the behavior of thebureaucrat is disregarded.

${ }^{18}$ We assume that the second order condition holds.
} 
To clarify the relationship between the bureaucrat's equilibrium migration quota $Q^{+}$and the interest groups' equilibrium proposed quotas with no government intervention in the quota proposal, $Q_{w}{ }^{* *}$ and $Q_{k}{ }^{* *}$, consider the first order condition (10) at the two migration quotas $Q_{w}{ }^{* *}$ and $Q_{k}{ }^{* *}$.

$$
\left.\frac{\partial G(.)}{\partial Q}\right|_{Q=Q_{i}^{* *}}=\left.\alpha \frac{\partial\left(E\left(u_{k}\right)+E\left(u_{w}\right)\right)}{\partial Q}\right|_{Q=Q_{i}^{* *}}+\left.(1-\alpha) \frac{\partial X}{\partial Q}\right|_{Q=Q_{i}^{* *}}, i=w, \mathrm{k}
$$

By the definition of $Q_{w}^{* *}$ and $Q_{k}^{* *},\left.\frac{\partial E\left(u_{w}\right)}{\partial Q}\right|_{Q=Q_{w}^{* *}}=0$ and $\left.\frac{\partial E\left(u_{k}\right)}{\partial Q}\right|_{Q=Q_{w}^{* *}}>0$ whereas $\left.\frac{\partial E\left(u_{w}\right)}{\partial Q}\right|_{Q=Q_{k}^{* *}}<0$ and $\left.\frac{\partial E\left(u_{k}\right)}{\partial Q}\right|_{Q=Q_{k}^{* *}}=0$. For the bureaucrat's equilibrium policy to coincide with one of the interest groups' equilibrium policies $Q_{w}{ }^{* *}$ or $Q_{k}{ }^{* *}$, one of the following equalities must be satisfied:

$$
\left.\frac{\partial G(.)}{\partial Q}\right|_{Q=Q_{i}^{* *}}=\left.\alpha \frac{\partial E\left(u_{j}\right)}{\partial Q}\right|_{Q=Q_{i}^{* *}}+\left.(1-\alpha) \frac{\partial X}{\partial Q}\right|_{Q=Q_{i}^{* *}}=0, \quad i=w, \text { or } \mathrm{i}=k
$$

or

$$
\left.\alpha \frac{\partial E\left(u_{j}\right)}{\partial Q}\right|_{Q=Q_{i}^{* *}}=-\left.(1-\alpha) \frac{\partial X}{\partial Q}\right|_{Q=Q_{i}^{* *}}, i=w, \text { or } \mathrm{i}=k
$$

Given that $\alpha$ and $(1-\alpha)$ are the weights the bureaucrat assigns to social welfare and to the total lobbying outlays, condition (13) requires that the marginal value of the lobbying outlays must equal the marginal value of social welfare. By (13), if $\frac{\partial X}{\partial Q}>0$, then the bureaucrat's equilibrium quota cannot coincide with the workers' equilibrium quota $Q_{w}{ }^{* *}$. And if $\frac{\partial X}{\partial Q}<0$, then the bureaucrat's equilibrium quota $Q^{+}$ cannot coincide with the capital owners' equilibrium quota $Q_{k}{ }^{* *}$. The bureaucrat's 
proposed quota $Q^{+}$can be between $Q_{w}{ }^{* *}$ and $Q_{k}{ }^{* *}$, and be represented by a point such as $\mathrm{C}$ in Figure 2. In such a case government intervention enhances compromise. However, it is possible that $Q^{+}$is higher than $Q_{k}{ }^{* *}$ or lower than $Q_{w}{ }^{* *}$. By (12), the former situation occurs, that is, $Q^{+}>Q^{* *}{ }_{k}$, if

$$
\left.\alpha \frac{\partial E\left(\begin{array}{ll}
u & w
\end{array}\right)}{\partial Q}\right|_{Q=Q_{k}^{* *}}>-\left.(1-\alpha) \frac{\partial X}{\partial Q}\right|_{Q=Q_{k}^{* *}}
$$

The latter situation occurs, that is, $Q^{+}<Q_{w}^{* *}$ if

$$
\left.\alpha \frac{\partial E\left(u_{k}\right)}{\partial Q}\right|_{Q=Q_{W}^{* *}}>-\left.(1-\alpha) \frac{\partial X}{\partial Q}\right|_{Q=Q_{w}^{* *}}
$$

Therefore, to satisfy (14), it must be the case that $\left.\frac{\partial X}{\partial Q}\right|_{Q=Q_{K}{ }^{* *}}>0$ and to satisfy (15), it must be that $\left.\frac{\partial X}{\partial Q}\right|_{Q=Q_{W}{ }^{* *}}<0$.

As we can see, all the conditions stated above are related to the relationship between a change in the proposed policy and the change in the lobbying efforts of the contestants, $\frac{\partial X}{\partial Q}$. The effect of a change in the proposed quota may have a positive, negative or no effect on the lobbying oulays. In the Appendix we present conditions that clarify the role of stakes-asymmetry and ability-asymmetry between the workers and the capital owners in determining the sign of $\frac{\partial X}{\partial Q}$. These conditions imply, in particular, that it is possible that the two contestants are induced to decrease their aggregate effort when the quota is increased. This occurs when the negative rival'sstake effect of the contestant who is induced to increase his effort more than counterbalances the sum of the two positive own-stake effects and his opponent's positive substitution effect. Notice that if the quota level is sufficiently high, 
$Q_{k}^{*}<Q$, then aggregate effort may increase. ${ }^{19}$

To sum up,

a. If a change in the migration quota positively (negatively) affects the total lobbying efforts of the workers and the capital owners, $\frac{\partial X}{\partial Q}>0 \quad\left(\frac{\partial X}{\partial Q}<0\right)$, then the bureaucrat's proposed quota cannot coincide with the workers ' (capital owners') proposed quota.

b. The bureaucrat's proposed quota can be more extreme than the quota proposed by the capital owners or by the workers.

While in Epstein and Nitzan (2005), it is argued that the proposed policy may be more extreme than the preferred proposals of the two groups, here we show conditions under which the migration quota will not coincide with that of one of the groups. Specifically, if the total effort invested in the contest is positively related to the proposed policy, then the proposed quota will not coincide with the worker's unions preferred policy and if the expenditure is negatively related to the proposed policy, then the policy will never coincide with the capital owners' preferred policy. This result establishes that the proposed policy of the bureaucrat may coincide with one of the proposals of the interests groups. This depends on the effect a change in the proposal has on the total lobbying efforts exerted by the interest groups. Moreover, the proposal can be more extreme than that proposed by either interest group. For example, for the bureaucrat to propose a quota that is higher than the

\footnotetext{
${ }^{19}$ Note that the two type of situations, the one where the interest groups determine the proposed policies and the one where the bureaucrat determines the proposed policy, can be combined in the following way: define $\operatorname{Pr}_{k}^{1}=\beta \operatorname{Pr}_{k}$ and $\operatorname{Pr}_{w}^{1}=\beta \operatorname{Pr}_{w}$, where $0<\beta \leq 1$. Then $\operatorname{Pr}_{k}+\operatorname{Pr}_{w}<1$ which implies that $1-\beta \geq 0$ is the probability that neither of the proposals by the lobbyists will be chosen. In other words, $1-\beta$ is the probability that the status-quo will be chosen by the bureaucrat. The bureaucrat will choose $\beta$ to maximize his payoff. If $\beta=1$, the bureaucrat will chose the statusquo. If the contest success function is $\operatorname{Pr}_{i}=\frac{x_{i}}{x_{j}+x_{i}}$ (Tullock, 1980), then the total expenditure of the groups is a linear function of $\beta$. Therefore, if the bureaucrat's objective is to maximize the resources invested in the contest, then he/she will choose a corner solution.
} 
quota proposed by the capital owners, total lobbying outlays must be positively related to the proposed quota at the policy proposed by the capital owners. The intuitive rationale behind this result is that the bureaucrat will only choose such a policy if he benefits from the proposed increase in the quota. Remember that an increase in the quota does not change the capital owners' stake, however, it does increase the workers' stake, namely it makes them worse off. Yet, if such a proposal increases the lobbying outlays, the bureaucrat may still gain from such a proposal. Clearly, the bureaucrat can only gain from such a proposal, if the increase in the quota results in an increase in the lobbying efforts. Under such circumstances the capital owners prefer a quota that exceeds the one supported by the workers. The equilibrium migration quota proposed by the bureaucrat may well be higher (or lower) than the quotas preferred by both the workers and the capital owners.

When the migration quota is higher (lower) than that preferred by the capital owners, migrants or local workers will be unemployed (there will be a shortage of workers). In the case of a higher migration quota, the capital owners do not have to employ the migrants and, therefore, as can be seen in Figure 2, their utility is not reduced when the quota is increased.

Let us now discuss how robust the results are to the assumption presented earlier that after a migration quota of $Q_{k}^{*}$ the profits of the capital owners either decrease or do not change. The question we would like to examine at this point is what happens if the profits continue to increase as a result of an increase in the number of migrants. Namely, there is no limit to the maximum number of migrants that the employers could use. Under this new assumption, the capital owners will always prefer more migrants and the workers will always want $Q_{w}^{*}$. Therefore, the bureaucrat's proposed quota can be more extreme than the quota proposed by the workers, however, it may equal to or be less than the optimal number of migrants of the capital owners (who may be interested in an infinite number of migrants). Result $b$ presented above would therefore remain valid for the workers, but it will no longer hold for the capital owners.

Let us finally consider how does $\alpha$, the weight assigned to social welfare, affect the proposed migration quota $Q^{+}$. Recall that an increase in $\alpha$ implies a reduction in the weight assigned to the lobbying outlays. A decrease in $\alpha$ can thus be interpreted as an indication that the government becomes more politicized as it cares 
more about its narrow interest and less about the public well being. The bureaucrat who is a leading player maximizes $G($.$) , being aware of the equilibrium lobbying$ outlays corresponding to the possible migration quotas. The first order condition that characterizes an interior sub-game perfect equilibrium quota proposal is stated in (10). This condition can be rewritten as

$$
\begin{gathered}
\frac{\partial\left(E\left(u_{w}\right)+E\left(u_{k}\right)\right)}{\partial Q}=-\frac{(1-\alpha)}{\alpha} \frac{\partial\left(x_{w}+x_{k}\right)}{\partial Q} \\
-\partial^{2} G(.)
\end{gathered}
$$

It can be verified that $\frac{\partial Q}{\partial \alpha}=\frac{-\partial^{2} G(.) / \partial Q \partial \alpha}{\partial^{2} G(.) / \partial Q^{2}}$. By the second order condition, $\frac{\partial^{2} G(.)}{\partial Q^{2}}<0$. As in Epstein and Nitzan (2003), by using the first order conditions, we therefore conclude that the derivative $\frac{\partial Q}{\partial \alpha}$ and the derivative $\frac{\partial X}{\partial Q}$ have opposite signs. That is, Sign $\left(\frac{\partial Q}{\partial \alpha}\right)=-\operatorname{Sign}\left(\frac{\partial X}{\partial Q}\right)$. Hence,

If a change in the quota positively (inversely) affects the total lobbying efforts, then a change in the weight assigned by the government to social welfare inversely (positively) affects the migration quota proposed by the bureaucrat.

This result emphasizes the critical significance of the sensitivity of $X$ to variations in the proposed quota $Q$ in determining the sensitivity of the optimal quota policy $Q$ to the parameter $\alpha$. In particular, an increase in $(1-\alpha)$, the degree of politicization of the government, may result in an increase or a decrease in the proposed migration quota. 


\subsection{The relationship between the status-quo and the proposed policy}

As we will show, the status-quo affects the policy proposed by the government. ${ }^{20}$ In order to explain this relationship, let us consider, for a fixed proposed policy, the effect of a change in the status-quo on the stakes and on the expected payoffs of the groups.

Recall that the stakes of the interest groups $n_{j}, j=w, k$, do not depend just on the policy chosen by the government $Q^{+}$, but also on the status-quo policy: the stakes are defined as $n_{k}\left(Q_{k}, Q_{s}\right)=\left|v_{k}\left(Q^{+}\right)-v_{k}\left(Q_{s}\right)\right|$ and $n_{w}\left(Q^{+}, Q_{s}\right)=\left|v_{w}\left(Q^{+}\right)-v_{w}\left(Q_{s}\right)\right|$, where $Q_{s}$ is the status- quo policy. The stakes are equal to the absolute difference between the two values of $v($.$) . For a certain interest$ group, the new proposal may be better or worse, relative to the status-quo,. For example, if the status-quo is $Q_{s}=\left(Q_{w}{ }^{* *}+Q_{k}{ }^{* *}\right) / 2$ and the proposed government policy is $Q_{k}^{* *}$, then the stake of the capital owner is $n_{k}\left(Q^{+}=Q_{k}^{* *}, Q_{s}=\frac{Q_{w}^{* *}+Q_{k}^{* *}}{2}\right)=\left|v_{k}\left(Q_{k}^{* *}\right)-v_{k}\left(\frac{Q_{w}^{* *}+Q_{k}^{* *}}{2}\right)\right|$ and the stake of the workers is $n_{w}\left(Q^{+}=Q_{k}^{* *}, Q_{s}=\frac{Q_{w}^{* *}+Q_{k}^{* *}}{2}\right)=\left|v_{w}\left(Q_{k}^{* *}\right)-v_{w}\left(\frac{Q_{w}^{* *}+Q_{k}^{* *}}{2}\right)\right|$. However, if the status-quo is $Q_{s}=Q_{w}{ }^{* *}$ and the government's proposal equals to $Q_{k}^{* *}$, then the union's stake will be $n_{k}\left(Q^{+}=Q_{k}^{* *}, Q_{s}=Q_{w}^{* *}\right)=\left|v_{k}\left(Q_{k}^{* *}\right)-v_{k}\left(Q_{w}^{* *}\right)\right|$ and the worker's stake will be $n_{w}\left(Q^{+}=Q_{k}^{* *}, Q_{s}=Q_{w}^{* *}\right)=\left|v_{w}\left(Q_{k}^{* *}\right)-v_{w}\left(Q_{w}^{* *}\right)\right|$. It is clear therefore that the stakes in the first example, $Q_{s}=\left(Q_{w}{ }^{* *}+Q_{k}{ }^{* *}\right) / 2$ and $Q^{+}=Q_{k}^{* *}$ are smaller than the stakes when $Q_{s}=Q_{w}{ }^{* *}$ and $Q^{+}=Q_{k}^{* *}$. That is,

$$
n_{k}\left(Q^{+}=Q_{k}^{* *}, Q_{s}=\frac{Q_{w}^{* *}+Q_{k}^{* *}}{2}\right)<n_{k}\left(Q^{+}=Q_{k}^{* *}, Q_{s}=Q_{w}^{* *}\right)
$$

and

$$
n_{w}\left(Q^{+}=Q_{k}^{* *}, Q_{s}=\frac{Q_{w}^{* *}+Q_{k}^{* *}}{2}\right)<n_{w}\left(Q^{+}=Q_{k}^{* *}, Q_{s}=Q_{w}^{* *}\right)
$$

\footnotetext{
${ }^{20}$ We thank an anonymous referee for pointing out this issue.
} 
The expected payoffs and expenditures of the groups will therefore be different under the two different situations. Hence, the optimal government proposals in these situations may be different. If the government's objective is to maximize the total amount of resources invested by the groups, $X$, and, the contest success function is $\operatorname{Pr}_{i}=\frac{x_{i}}{x_{i}+x_{j}}$ (Tullock, 1980), then it can be shown that the total expenditure in the contest will be equal to:

$$
X^{*}=\frac{n_{w} n_{k}}{n_{w}+n_{k}}
$$

For a given government's proposal, $Q^{+}$, let us examine how the total amount of resources invested in the contest are affected by a change in the status-quo:

$$
\frac{\partial X^{*}}{\partial Q_{s}}=\frac{n_{k} n_{w} n_{k}^{\prime}}{\left(n_{w}+n_{k}\right)^{2}}\left(\frac{\eta_{w}}{\eta_{k}}+\frac{n_{w}}{n_{k}}\right)
$$

where $\eta_{j}=\frac{\partial n_{j}}{\partial Q_{s}} \frac{Q_{s}}{n_{j}}=n^{\prime}{ }_{j} \frac{Q_{s}}{n_{j}}$ is the elasticity of player $j$ 's stake (benefit) with respect to a change in the status-quo. Consider the case where the status-quo is the number of migrants that maximizes the workers' stake, $Q_{w}^{*}$, and this is also the government's proposal. In this case there will be no contests and the total expenditure would be equal to zero, $X^{*}=0$. If the status-quo is higher than $Q_{w}^{*}$ and lower than $Q_{k}^{*}$, then the higher the status-quo, the larger are the stakes of the groups: $\frac{\partial n_{j}}{\partial Q_{s}}=n^{\prime}{ }_{j}>0$ and $\eta_{j}>0, j=w, k$, and therefore $\frac{\partial X^{*}}{\partial Q_{s}}>0$.

On the other hand, if the government's proposal is $Q_{k}^{*}$ and the status-quo is lower than $Q_{k}^{*}$ and higher than $Q_{w}^{*}$, then a higher status-quo level will increase the worker's stakes while it will decrease the capital owner's stakes, $\frac{\partial n_{w}}{\partial Q_{s}}>0, \frac{\partial n_{k}}{\partial Q_{s}}<0, \eta_{w}>0$ and $\eta_{k}<0$ and therefore the sign of $\frac{\partial X^{*}}{\partial Q_{s}}$ is not clear. 
The sign of $\frac{\partial X^{*}}{\partial Q_{s}}$ depends on the relationship between the stakes and the elasticities in the following way: if $-\frac{\eta_{w}}{\eta_{k}}=\frac{n_{w}}{n_{k}}$, then $\frac{\partial X^{*}}{\partial Q_{s}}=0$. In other words, increasing the status-quo decreases the capital owners' stake and thus they may invest less effort in the contest while at the same time the workers' stake is increased and this may increase their investment. The net effect on the total expenditures is unclear.

The examples above illustrate that different status-quo levels may give rise to different proposed policies. In general, it is not clear how a change in the status quo will affect the optimal proposed government's policy. It is clear, however, that for each status-quo there is an optimal policy. In order to clarify the exact relationship between the proposed policy and the status-quo, one must calculate the sensitivity of the optimal government's policy with respect to changes in the status-quo, namely, $\frac{\partial Q^{+}}{\partial Q_{S}}$. It can be verified that $\frac{\partial Q^{+}}{\partial Q_{S}}=\frac{-\partial^{2} G(.) / \partial Q \partial Q_{S}}{\partial^{2} G(.) / \partial Q^{+2}}$. Since $\frac{\partial^{2} G(.)}{\partial Q^{+2}}<0$, the sign of $\frac{\partial Q^{+}}{\partial Q_{S}}$ equals to the sign of $\frac{\partial^{2} G(.)}{\partial Q \partial Q_{S}}$. G(.) depends on both of the expected net payoff of the interest groups and on the total expenditure of the groups. Therefore, as we have seen above, the status quo will affect both the expected net payoffs and the expenditures of the groups. We may conclude that,

The status-quo affects government's proposed policy.

The fact that the status-quo affects the proposed policy may well have many political consequences. For example, a government in power can determine a policy that will become the status-quo in the next period, in order to affect future changes in the policy, see for example Glazer, Gradstein and Konrad (1998) who provide conditions under which politicians in power determine policies that become the status-quo and by doing so directly affect the probability of being re-elected. Moreover, if the bureaucrat can propose policy changes in every period, he may wish 
to make few changes, one in each period, rather than one change in the first period. A possible reason for behavior is that, by creating many contests rather than one contest, the bureaucrat may increases his own expected payoff. On the other hand, the bureaucrat may propose a very extreme policy with a very small probability of approval. Such extreme policy may have a low probability of being approved; however, it may generate a high return to the bureaucrat. The bureaucrat may propose such extreme "negative" policies, if he knows that in the next period it can create a contest with an outcome that compensates for his reduced return yield in the previous period.

When we compare the determination of quotas for high and low-skilled migrants the status-quo may well play a major role. There seems to be less opposition to high-skilled migrants than to low skilled migrants (see, for example, Boeri, Hanson and McCormick, 2002 and Dustmann and Preston 2004). Thus, if the government wishes to increase resources invested by the interest groups, then it will probably need to propose more extreme quotas for high- skilled workers than for lowskilled workers.

\section{Concluding remarks}

In this paper we analyze the endogenous determination of migration quota in a political-economic setting. We describe a contest between two interest groups, local workers (representing those groups that oppose migration) and capital owners who have different preferences regarding the migration quota. The capital owners prefer a larger quota relative to the workers. The two groups have conflicting interests regarding the approval or rejection of the proposed migration policy.

We began by identifying the non-strategic optimal quotas of the interest groups assuming that the proposed policy is independent of their behaviour. We then introduced the first strategic game where the interest groups propose alternative quotas and the bureaucrat determines which policy is approved. In this setting the government does not intervene in the determination of the quota proposal. By the first result, the effect of lobbying on the random behaviour of the bureaucrat is compromise enhancing. That is, both the workers and the capital owners moderate their proposals when lobbying affects the approval of their supported policies. However, even though lobbying induces the contestants to propose "closer” policies, the proposals do not coincide. 
In contrast to the first result, the effect of government intervention in determining the proposed quota on the nature of the quota is ambiguous. That is, when a bureaucrat proposes a migration quota, his proposed quota need not be compromise enhancing relative to the proposal of the workers or the capital owners in the previous case. The implemented quota can even be more extreme (higher) than the optimal quota of the capital owners in the non-strategic setting. The second result specifies the conditions that give rise to moderate and extreme quota determination by the government. In contrast to Epstein and Nitzan (2005), we provide conditions that ensure that the proposed policy will never coincide with one of the groups' preferred policy and we show that the proposed policy depends on the existing status-quo. In different economies with different status-quos we will see different proposals. In other words, the existing status-quo policy plays a major role in determining the proposed policy

Finally, we consider the effect of changes in the weight assigned by the bureaucrat to the public well being on the proposed quota. It has been shown that a decrease in the weight assigned by the bureaucrat to social welfare may increase or decrease the migration policy. The ambiguity is due to the ambiguity of the effect of a change in the proposed migration policy on the total lobbying efforts of the workers and the capital owners in the contest over the approval or rejection of the proposed quota. The conditions resolving this ambiguity are derived in the Appendix.

The struggle over migration policy is becoming a very important issue in the EU and in the US. Our results provide some preliminary insights into the economics behind the struggle over migration policy. In particular, they clarify the role of strategic lobbying, the role of government intervention in the determination of the proposed quota and the role of the nature of the government (the weight it assigns to social welfare relative to the lobbying outlays) on the migration quotas in different countries. 


\section{References}

Amegashie J. A., 2004, “A political economy model of immigration quotas", Economics of Governance, 5, 255-267.

Baik, K.H., 1999, "Rent-seeking firms, consumer groups and the social costs of monopoly”, Economic Inquiry, 37(3), , 542-554.

Baik, K.H and I. G. Kim, 1997, "Delegation in contests", European Journal of Political Economy 13, 281-298.

Bauer, T.K. and K. F. Zimmermann, ed., 2002, The Economics of Migration, Edward Elgar Publishing.

Baye, M.R. and U. Shin, 1999, "Strategic behavior in contests: comment", American Economic Review 89 (3), 1999,691-698.

Benhabib, J., 1996, “On the political economy of immigration”, European Economic Review 40, 1737-1743.

Boeri T., Hanson G. and B. McCormick, ed., 2002 Immigration Policy and the Welfare System, Oxford University Press.

Borjas, G.J., 1994, “The economics of immigration”, Journal of Economics Literature 32, 1667-1717.

Borjas, G.J., 1995, “The economic benefits if immigration of immigration”, Journal of Economic Perspectives 9, 3-22.

Borjas, G. J., 1999, Heaven’s Door. Princeton: Princeton University Press.

Buckley, F.H. 1996, “The Political Economy of Immigration Policies”, International Review of Law and Economics; 16(1), 81-99.

Carrington, W.J., Detragiache, E. and Vishwanath, T. (1996): "Migration with Endogenous Moving Costs” American Economic Review, 86(4), 909-30.

Chiswick, B.R. and Miller, P.M, 1996, "Ethnic Networks and Language Proficiency among Immigrants”, Journal of Population Economics, 9(1), 19-35.

Church, J. and King, I., 1983, "Bilingualism and Network Externalities”, Canadian Journal of Economics; 26(2), 337-45.

Cukierman, A., Hercowitz, Z. and Pines, D. 1993, "The Political Economy of Immigration” Tel Aviv Foerder Institute for Economic Research Working Paper 17/93.

Dixit , A., 1987, "Strategic behavior in contests", American Economic Review 77, 891-898. 
Dustmann, C. and Preston I., 2004, Is Immigration Good or Bad for the Economy? Analysis of Attitudinal Responses", CReAM Discussion Paper No 06/04.

Ellingsen, T., 1991, "Strategic buyers and the social cost of monopoly", American Economic Review 81(3), 648-657.

Epstein G.S., 2003, "Labor market interactions between legal and illegal immigrants”, Review of Development Economics, 7(1), 30-43.

Epstein G.S., A. L. Hillman, 2003, "Unemployed immigrants and voter sentiment in the welfare state”, Journal of Public Economics, 87, 1641-1655.

Epstein G.S., A.L. Hillman and A. Weiss, 1999, “Creating illegal immigrants”, Journal of Population Economics, 12(1), pp. 3-21.

Epstein G.S. and S. Nitzan, 2005, "Lobbying and Compromise" Public Choice, forthcoming.

Epstein G.S. and S. Nitzan, 2004, “Strategic restraint in contests", European Economic Review, 48, 201-210.

Epstein G.S. and S. Nitzan, 2003, "Political culture and monopoly price determination”, Social Choice and Welfare, 21, 1-19.

Epstein G.S. and S. Nitzan, 2002a, "Public-policy contests, politicization and welfare", Journal of public Economic Theory, 4 (4), 661-677.

Epstein G.S. and S. Nitzan, 2002b, "The Politics of Randomness" CESifo Working paper no. 803.

Ethier, W.J., 1986 “Illegal immigration: the host country problem”, American Economic Review, 76, 56-71.

Fabella, R.V., 1995, "The social cost of rent seeking under countervailing opposition to distortionary transfers”, Journal of Public Economics, 57, 235-247.

Gang, I.N, and Rivera-Batiz F. 1994 "Labor Market Effects of Immigration in the United States and Europe: Substitution vs. Complementarity," Journal of Population Economics, 7, 157-175

Glazer , A. Gradstein M. and Konrad K.A., 1998, "The Electoral Politics of Extreme Policies", The Economic Journal, 108(451), 1677-1685.

Gottlieb, P., 1987, Making Their Own Way: Shorthorn Blacks' Migration to Pittsburgh, 1916-30, Urbana: University of Illinois Press.

Grossman, G. and E. Helpman, 2001, Special Interest Politics, Cambridge: M.I.T. Press. 
Grossman, G. and E. Helpman, 1996, "Electoral competition and special interest politics", Review of Economic Studies, 63, 265-286.

Hillman A.L. and A. Weiss, 1999, “A theory of permissible illegal immigration”, European Journal of Political Economy” 15, 585-604.

Mundell R.A., 1957, "International trade and factor mobility”, American Economic Review, 47(3), 321-335.

Nitzan, S., 1994, “Modelling rent-seeking contests”, European Journal of Political Economy 10(1), 41-60.

Nti, K.O., 1999, "Rent seeking with asymmetric valuations”, Public Choice, 98, 415430.

Persson, T. and G. Tabellini, 2000, Political Economics: Explaining Economic Policy, Cambridge: M.I.T. Press.

Schmidt, T., 1992, "Rent-seeking firms and consumers: an equilibrium analysis", Economics and Politics 4(2), 137-149.

Schmidt, C. M., Stilz, A., and K. F. Zimmermann, 1994, "Mass migration, unions, and government intervention", Journal of Public Economics, 55, 185-201.

Smith J. P. and Edmonston B., Editors, 1997, Panel on the Demographic and Economic Impacts of Immigration, National Research Council. http://books.nap.edu/catalog/5779.html

Sollner, F. 1999, “A Note on the Political Economy of Immigration” Public-Choice 100(3-4), 245-51.

Storesletten, K., 2000, "Sustaining fiscal policy through immigration", Journal of Political Economy, 108, 300-323.

Tullock, G., 1980, “Efficient Rent-Seeking”, In Buchanan, J.M., Tollison, R.D. and Tullock, G., Toward a Theory of the Rent-Seeking Society. College Station, TX: Texas A. and M. University Press. 1980, 97-112.

Zimmermann, K.F., 1995, "Tackling the European migration problem", Journal of Economics Perspectives, 9, 45-62. 
Figure 1

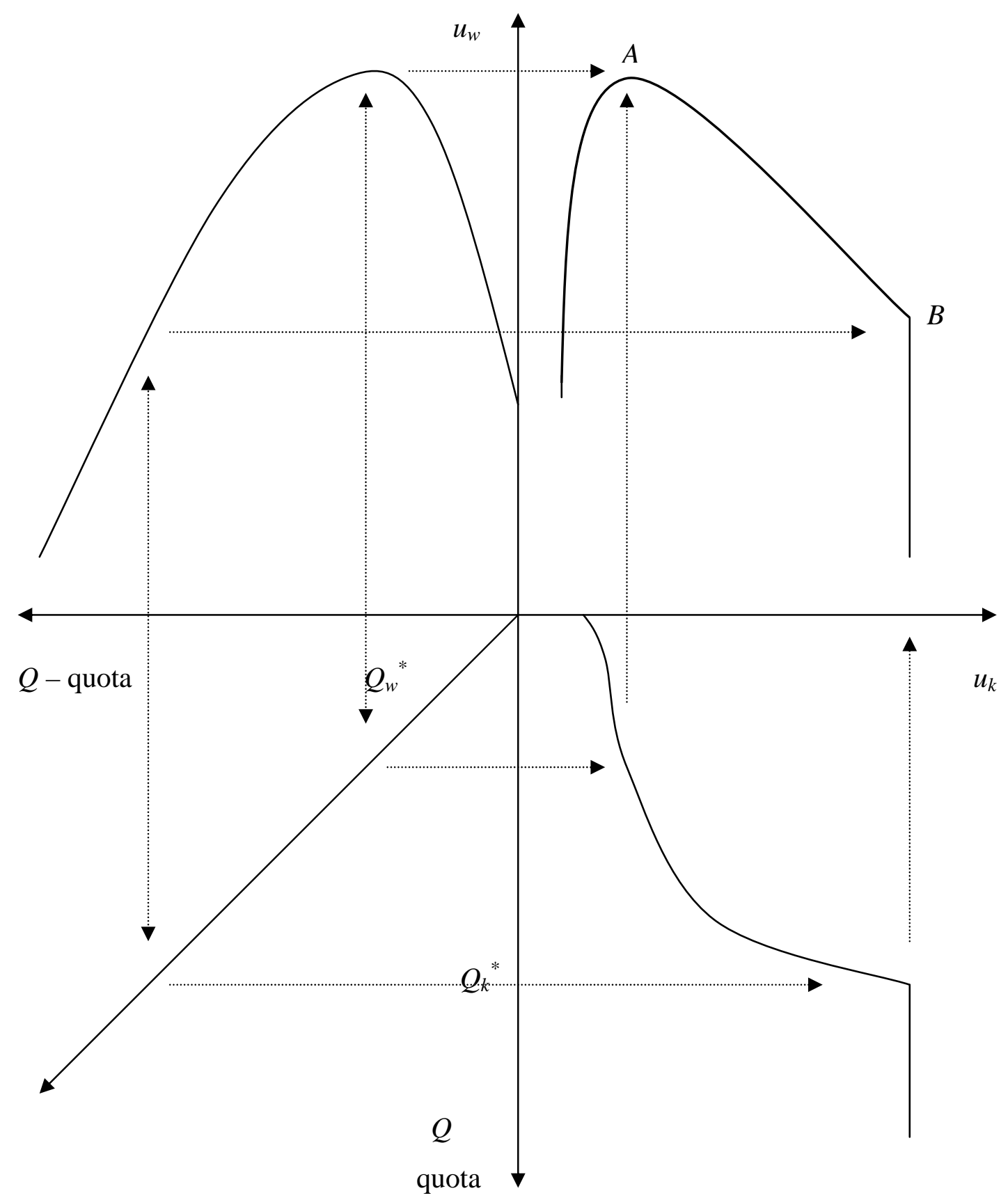


Figure 2

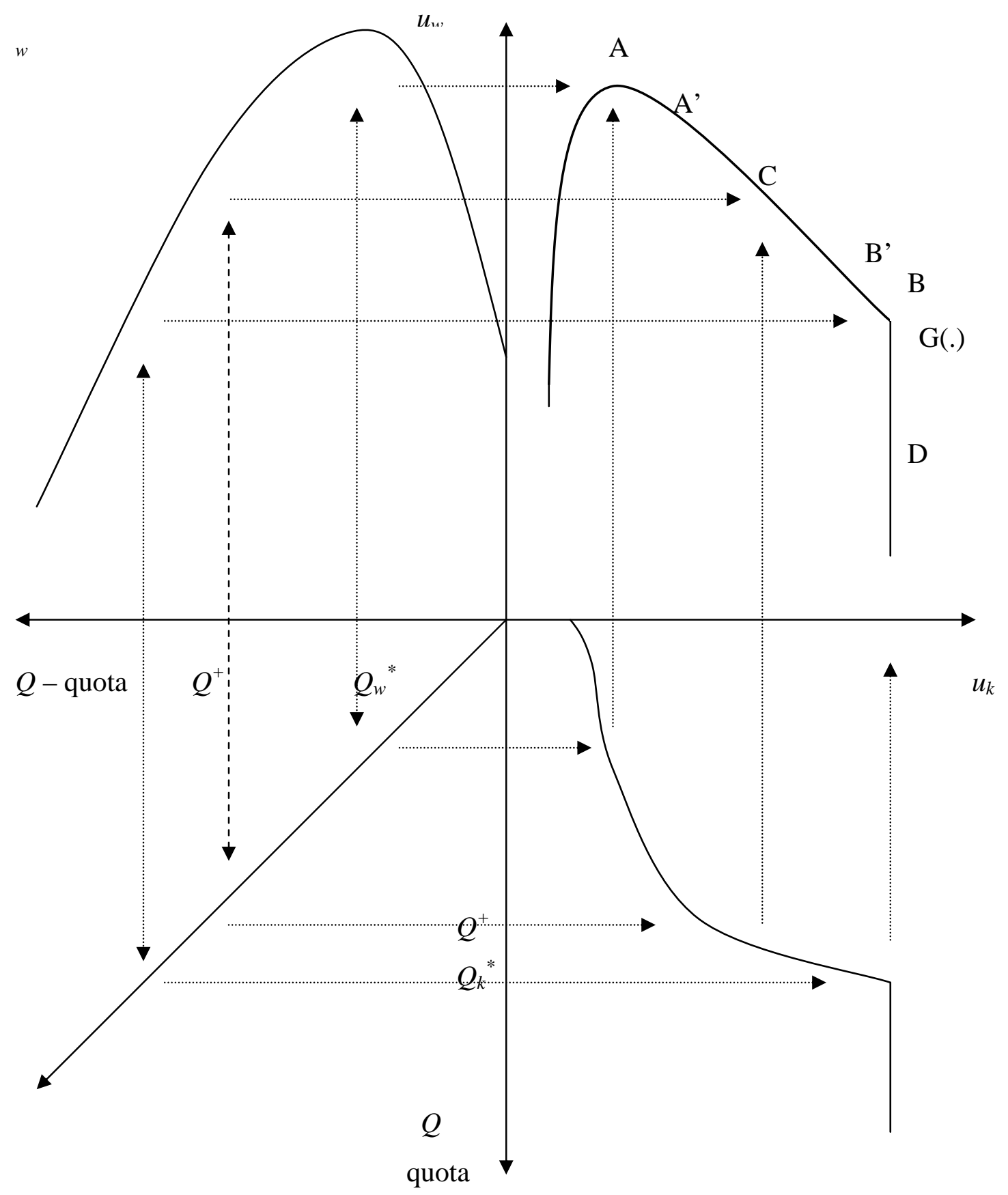




\section{Appendix}

Using (6) with $Q_{i}=Q$, we obtain that the Nash equilibrium efforts satisfy the following conditions:

$$
\frac{\partial x_{i}^{* *} i_{i}}{\partial Q}=\frac{n_{i} \frac{\partial^{2} \operatorname{Pr}_{i}}{\partial x_{i} \partial x_{j}} \frac{\partial \operatorname{Pr}_{j}}{\partial x_{j}} \frac{\partial n_{j}}{\partial Q}-n_{j} \frac{\partial^{2} \operatorname{Pr}_{j}}{\partial x_{j}{ }^{2}} \frac{\partial \operatorname{Pr}_{i}}{\partial x_{i}} \frac{\partial n_{i}}{\partial Q}}{n_{i} n_{j}\left(\frac{\partial^{2} \operatorname{Pr}_{j}}{\partial x_{j}{ }^{2}} \frac{\partial^{2} \operatorname{Pr}_{i}}{\partial x_{i}{ }^{2}}-\frac{\partial^{2} \operatorname{Pr}_{i}}{\partial x_{i} \partial x_{j}} \frac{\partial^{2} \operatorname{Pr}_{j}}{\partial x_{i} \partial x_{j}}\right)} \quad, i \neq j, i, j=w, k
$$

Rewriting (a1) together with the first order conditions, we obtain that:

$$
\frac{\partial x_{i}^{* *}}{\partial I}=\frac{1}{B} \frac{\partial^{2} \operatorname{Pr}_{i}}{\partial x_{i} \partial x_{j}} \eta_{j} n_{i}-\frac{1}{B} \frac{\partial^{2} \operatorname{Pr}_{j}}{\partial x_{j}^{2}} \eta_{i} n_{j} \quad, i \neq j, \quad i, j=w, k
$$

where $B=Q n_{i} n_{j}\left(\frac{\partial^{2} \operatorname{Pr}_{j}}{\partial x_{j}{ }^{2}} \frac{\partial^{2} \operatorname{Pr}_{i}}{\partial x_{i}{ }^{2}}-\frac{\partial^{2} \operatorname{Pr}_{i}}{\partial x_{i} \partial x_{j}} \frac{\partial^{2} \operatorname{Pr}_{j}}{\partial x_{i} \partial x_{j}}\right)>0$ and $\eta_{j}=\frac{\partial n_{i}}{\partial Q} \frac{Q}{n_{i}}$. All values are computed at the Nash equilibrium. The effect of a change in the quota on the total effort invested in the contest by the capital owners and the workers, $X^{*}$, is given by:

$$
\begin{aligned}
& \frac{\partial X^{+}}{\partial Q}=\frac{\partial x^{*}{ }_{k}}{\partial Q}+\frac{\partial x^{*}{ }_{w}}{\partial Q}= \\
& \frac{1}{B}\left(\frac{\partial^{2} \operatorname{Pr}_{k}}{\partial x_{k} \partial x_{w}}\left(\eta_{L} n_{k}-\eta_{k H} n_{w}\right)-\left(\frac{\partial^{2} \operatorname{Pr}_{k}}{\partial x_{k}{ }^{2}} \eta_{w} n_{k}+\frac{\partial^{2} \operatorname{Pr}_{w}}{\partial x_{w}{ }^{2}} \eta_{k} n_{w}\right)\right)
\end{aligned}
$$

Hence,

If $Q_{k}^{*}>Q>Q^{*}{ }_{w}$ then

$$
\frac{\partial X^{+}}{\partial Q} \geq 0 \Leftrightarrow \frac{\partial^{2} \operatorname{Pr}_{k}}{\partial x_{k} \partial x_{w}}\left(\eta_{w} n_{k}-\eta_{k} n_{w}\right) \frac{\geq}{<} \frac{\partial^{2} \operatorname{Pr}_{k}}{\partial x_{k}{ }^{2}} \eta_{w} n_{k}+\frac{\partial^{2} \operatorname{Pr}_{w}}{\partial x_{w}{ }^{2}} \eta_{k} n_{w}
$$

and if $Q_{k}^{*}<Q$ then $\frac{\partial X^{+}}{\partial Q} \geq 0 \Leftrightarrow \frac{\partial^{2} \operatorname{Pr}_{k}}{\partial x_{k} \partial x_{w}} /-\frac{\partial^{2} \operatorname{Pr}_{k}}{\partial x_{k}{ }^{2}}<-1$ 